(CRP) and autoantibody profile were analyzed. Quantitative and categorical data were compared using Kruskal-Wallis test and chi-square test, respectively. Results: There was a difference in prevalence of malar rash between the groups $(\mathrm{p}=0.022)$ : it was more common in JSLE $(40.4 \%)$ and ASLE $(34.4 \%)$ than in LSLE patients (15.6\%; $p=0.04$ and 0.05 , respectively). Similar distribution was found for renal involvement: JSLE and ASLE patients presented higher rates of nephritis (55.8\% and $49.4 \%$, respectively) than LSLE patients $(23.8 \%$; $p=0.012$ and 0.014 , respectively). But the groups did not differ significantly with regard to nephrotic syndrome $(p=0.224)$. ASLE was associated with more frequent alopecia $(38.8 \%)$ comparing with JSLE $(19.2 \% ; p=0.04)$. Moreover, ASLE patients also had the highest frequency of lymphadenopathy (56.3\%) whereas in LSLE it was observed only in $25.0 \%$ of patients $(p=0.001)$. Serositis was more common in LSLE (54.5\%) and ASLE (43.8\%) than in JSLE (23.1\%; $p=0.011$ and 0.034 , respectively). Although secondary Sjögren's syndrome was more frequently observed in ASLE (7.6\%) and LSLE (7.3\%) than in JSLE $(0.0 \%)$, the difference did not achieve statistical significance $(p=0.157)$. Also, no differences were observed in the occurence of arthritis, pulmonary and neurological manifestations, constitutional symptoms, SLEDAI score among the groups. Median CRP level in LSLE was significantly higher $(14.0(1.1-46.4) \mathrm{mg} / \mathrm{L})$ than in JSLE $(0.7$ $(0.0-12.0) \mathrm{mg} / \mathrm{L})(\mathrm{p}<0.05)$. But all groups did not differ significantly with regard to ESR levels. When differences in antinuclear antibodies were analyzed, we disclosed that the frequency of anti-dsDNA positive results was significantly higher in JSLE $(68.6 \%)$ and ASLE $(70.1 \%)$ patients when compared with that found in LSLE patients $(31.3 \%)(p=0.016$ and 0.001 , respectively). There were no significant differences between groups with regard to positivity for other antibodies (anti-Sm, -Ro, -La, -RNP, antiphospholipid antibodies).

Conclusion: JSLE and ASLE patients are more likely to have malar rash, nephritis and anti-dsDNA positivity. Alopecia and lymphadenopathy are most frequent in ASLE patients. JSLE are far less likely to have serositis than any other group. Patients with LSLE demonstrate comparatively low frequency of major organ involvement, but they have higher levels of CRP.

REFERENCES:

[1] Ambrose N., et al. Differences in disease phenotype and severity in SLE across age groups. Lupus. 2016;25(14):1542-1550.

[2] Livingston B., et al. Differences in autoantibody profiles and disease activity and damage scores between childhood- and adult-onset systemic lupus erythematosus: a meta-analysis. Seminars in Arthritis and Rheumatism. 2012;42(3):271-280.

Disclosure of Interests: None declared

DOI: 10.1136/annrheumdis-2021-eular.1237

\section{POS0726 POST-TRAUMATIC STRESS DISORDER AND QUALITY OF LIFE IN SYSTEMIC LUPUS ERYTHEMATOSUS. A CROSS SECTIONAL WEB SURVEY-BASED STUDY}

\author{
L. Moroni ${ }^{1,2}$, M. Mazzetti ${ }^{3}$, G. A. Ramirez ${ }^{1,2}$, S. Zuffada ${ }^{3}$, N. Farina ${ }^{1,2}$, \\ E. Bozzolo ${ }^{1}$, V. Di Mattei ${ }^{2,3}$, L. Dagna ${ }^{1,2}$. ${ }^{1}$ San Raffaele Hospital, Unit of \\ Immunology, Rheumatology, Allergy and Rare Diseases, Milano, Italy; ${ }^{2}$ Vita- \\ Salute San Raffaele University, Milano, Italy; ${ }^{3}$ San Raffaele Hospital, Clinical \\ and Health Psychology Unit, Milano, Italy
}

Background: Exposure to severe or chronic life stressors may alter immune function and high levels of subsequent distress have been implicated in autoimmune disease pathogenesis. Post-traumatic stress disorder (PTSD) is a debilitating psychiatric condition affecting $1-12 \%$ of the general population ${ }^{1}$, occurring in response to traumatic events. Growing evidence supports an association between trauma exposure and PTSD with systemic lupus erythematosus (SLE) onset $^{2}$.

Objectives: To cross-sectionally assess PTSD prevalence in a cohort of patients with SLE and to examine its correlation with quality of life.

Methods: A 189-item anonymous questionnaire including demographics, disease features, the 9-domain Trauma and Loss Spectrum - Self Report (TALS-SR) and the 8-domain Lupus Quality of Life (Lupus QoL) was administered via web to a cohort of patients with SLE. Patients were classified as PTSD cases based on TALS-SR items corresponding to the Diagnostic and Statistical Manual of Mental Disorders, Fifth Edition (DSM-5) criteria for PTSD.

Results: Ninety-nine ( $95 \%$ female and $5 \%$ male) patients with a median follow-up of 16.5 years completed the questionnaire. Self-reported fatigue prevalence was $75 \%$. Fifteen patients $(15 \%)$ reportedly were on psychological and/or psychiatric support. Thirty-one patients (31\%) met the DSM-5 criteria for PTSD. The average LupusQoL interdomain score was 80/100. PTSD cases reported significantly lower scores compared to non-cases in three LupusQoL domains: planning ( 83 vs. $100, p=0.035$ ), body image ( 85 vs. $95, p=0.031$ ), and fatigue (67 vs. $92, p=0.001$ ). An inverse correlation between TALS-SR scores and Lupus QoL subscales was found (Table1). In particular, the degree of stress secondary to losses or upsetting events was strongly correlated to fatigue intensity (rho $=-0.458, \mathrm{p}<0.001$ )
Conclusion: PTSD prevalence might be higher in SLE than in the general population and have a detrimental influence on quality of life. Fatigue perception might be more significantly affected by PTSD. Intervention studies are needed to assess the therapeutical effects of psychological support in patients with SLE. REFERENCES:

[1] Shalev A et al. Post-Traumatic Stress Disorder. New England Journal of Medicine, June 2017.

[2] Roberts AL et al. Association of Trauma and Posttraumatic Stress Disorder With Incident Systemic Lupus Erythematosus in a Longitudinal Cohort of Women. Arthritis \& Rheumatology, November 2017

Table 1. Spearman rho coefficients outlining correlation across Lupus QoL and TALS-SR domains. The highest negative correlation has been found between fatigue and reaction to traumatic events. Significant correlations boxes are coloured in yellow (weak, rho 0.20-0.39) and red (moderate, rho $0.40-0.59)$. * $p<0.05,{ }^{\star \star} ~ p<0.01$.

\begin{tabular}{|c|c|c|c|c|c|c|c|c|c|c|}
\hline & & \multicolumn{8}{|c|}{ LupusQoL Domains } & \multirow[b]{2}{*}{$\begin{array}{c}\text {-Lupus } \\
\text { QoL } \\
\text { Total } \\
\text { Score }\end{array}$} \\
\hline & & $\begin{array}{c}\text { Physical } \\
\text { health }\end{array}$ & Pain & Planning & $\begin{array}{l}\text { Intimate } \\
\text { relation- } \\
\text { ships }\end{array}$ & $\begin{array}{l}\text { Burden } \\
\text { to } \\
\text { others }\end{array}$ & $\begin{array}{l}\text { Emotional } \\
\text { health }\end{array}$ & $\begin{array}{l}\text { Body } \\
\text { image }\end{array}$ & Fatigue & \\
\hline \multirow{9}{*}{$\begin{array}{l}\text { TALS-SR } \\
\text { Domains }\end{array}$} & Loss events & -.217 & -.217 & -.096 & -.031 & .047 & -.022 & .076 & -.009 & -.061 \\
\hline & Grief reactions & -.145 & -.104 & -.041 & -.018 & -.124 & -.172 & -.192 & -.149 & -.107 \\
\hline & $\begin{array}{l}\text { Potentially } \\
\text { traumatic } \\
\text { events }\end{array}$ & .039 & -.082 & -.169 & -.167 & -.207 & -.185 & -.046 & -.229 & -.096 \\
\hline & $\begin{array}{l}\text { Reaction to } \\
\text { losses or } \\
\text { upsetting } \\
\text { events }\end{array}$ & -.221 & $-.256^{*}$ & $-.289^{*}$ & -.218 & $-.290^{*}$ & $-.369^{* *}$ & $-.371^{* *}$ & -.458 & $-.341^{* *}$ \\
\hline & $\begin{array}{l}\text { Re- } \\
\text { experiencing }\end{array}$ & -.139 & -.215 & $-.245^{*}$ & -.228 & $-.320^{* *}$ & $-.275^{*}$ & $-.287^{*}$ & -.342 & -.274 \\
\hline & $\begin{array}{l}\text { Avoidance } \\
\text { and numbing }\end{array}$ & -.176 & $-.246^{*}$ & $-.279^{*}$ & $-.257^{*}$ & $-.337^{* *}$ & $-.405^{\circ "}$ & $-.413^{\prime \prime}$ & -.406 & -.338 \\
\hline & $\begin{array}{l}\text { Maladaptive } \\
\text { coping }\end{array}$ & -.190 & -.238 & -.294 & $-.282^{*}$ & $-.324^{* *}$ & $-.340^{* *}$ & $-.358^{* *}$ & $-.405^{*}$ & $-.327^{* *}$ \\
\hline & Arousal & -.134 & -.177 & -.263 & $-.320^{\circ 1}$ & $-.283^{*}$ & $-.279^{*}$ & $-.321^{\prime \prime}$ & -.397 & -.282 \\
\hline & $\begin{array}{l}\text { Personal } \\
\text { characteristics / } \\
\text { risk factors }\end{array}$ & $t^{-.044}$ & -.115 & $-.266^{\star}$ & -.189 & $-.409^{* *}$ & -.231 & -.197 & $-.253^{*}$ & -.199 \\
\hline
\end{tabular}

Disclosure of Interests: Luca Moroni: None declared, Martina Mazzetti None declared, Giuseppe Alvise Ramirez: None declared, Simone Zuffada: None declared, Nicola Farina: None declared, Enrica Bozzolo: None declared Valentina Di Mattei: None declared, Lorenzo Dagna Consultant of: Abbvie, Amgen, Biogen, BristolMyers Squibb, Celltrion, Galapagos, GlaxoSmithKline, Novartis, Pfizer, Roche, Sanofi-Genzyme, and SOBI, Grant/research suppor from: The Unit of Immunology, Rheumatology, Allergy and Rare Diseases (UnIRAR) received unresctricted research/educational grants from Abbvie, Bristol-Myers Squibb, Celgene, GlaxoSmithKline,Janssen, Merk Sharp \& Dohme, Mundipharma Pharmaceuticals, Novartis, Pfizer, Roche, Sanofi Genzyme, and SOBI

DOI: 10.1136/annrheumdis-2021-eular.1238

\section{POS0727 INSULIN RESISTANCE AND LEPTIN LEVELS IN SYSTEMIC LUPUS ERYTHEMATOSUS PATIENTS WITHOUT DIABETES MELLITUS OR FASTING HYPERGLYCEMIA}

L. Kondrateva ${ }^{1}$, T. Panafidina ${ }^{1}$, T. Popkova ${ }^{2}$, M. Cherkasova ${ }^{3}$, A. Lila ${ }^{4}$, E. Nasonov ${ }^{4}{ }^{1}$ V.A. Nasonova Research Institute of Rheumatology, Department of Systemic Rheumatic Diseases, Moscow, Russian Federation; ${ }^{1} \mathrm{~V}$.A. Nasonova Research Institute of Rheumatology, Department of Systemic Rheumatic Diseases, Moscow, Russian Federation; ${ }^{3}$ V.A. Nasonova Research Institute of Rheumatology, Immunology and Molecular Biology of Rheumatic Diseases, Moscow, Russian Federation; ${ }^{4}$ V.A. Nasonova Research Institute of Rheumatology, Scientific Department, Moscow, Russian Federation

Background: Insulin resistance (IR) is considered as initial stage of diseases continuum from development of prediabetes to eventual progression to type 2 diabetes mellitus (T2DM). Individuals with prediabetes have also elevated leptin levels, so this adipocytokine along with IR can be considered as predictive laboratory markers of higher risk of T2DM. It is not yet clear whether presence of individual or multiple SLE-related and/or known traditional risk factors of T2DM (such as unhealthy diet, physical inactivity, family history of diabetes, or being overweight) can precipitate the development of IR.

Objectives: To analyze the relationship between IR and increasing leptin levels rates. To identify the presence and evaluate the potential role of traditional and disease-related risk factors for IR in SLE patients without T2DM or hyperglycemia. 